\title{
The Application Status and Development of Patent Technology of Temporary Work Shed Construction in China
}

\author{
Zhijian Yang ${ }^{a}$, Zhihua Su ${ }^{b}$, Guochang $\mathrm{Li}^{\mathrm{c}}$, and Yidi Liu ${ }^{\mathrm{d}}$ \\ School of Civil Engineering, Shenyang Jianzhu University, Shenyang 110168, China \\ afaemail@163.com, ${ }^{\text {bhua9181@sina.com, }}$ liguochang0604@sina.com,
}

Keywords: steel structure; temporary work shed; application status; patant review.

\begin{abstract}
In recent years, China is vigorously to develop the prefabricated building and advocate green construction, aimed at maximizing the conservation of resources and reducing carbon emissions. In the construction industry to expand the scale at the same time, it is necessary to scientific management and optimal allocation, as much as possible to reduce construction costs and adverse environmental impact. Temporary work shed is an important part of the temporary facility of the construction site.The design, produce, transport, install, maintain and turnover of the whole life cycle can greatly reduce the energy consumption of temporary facilities. In this paper, the application status of the temporary work shed of steel structure in China's construction site is reviewed, and the development of temporary work shed of steel structure is reviewed from the perspective of patent technology in China.
\end{abstract}

\section{Introduction}

Steel structure has good mechanical processing performance, easy assembly, light and high strength, suitable for modularization, standardization, industrialization, prefabrication and informatization of the building, in line with the development concept of innovation, coordination, green, open and shared $^{[1]}$. In recent years, our country has increased efforts to support the development of prefabricated steel structure buildings, and continuously increasing the proportion of prefabricated buildings in new buildings. In order to ensure safety, cost saving, energy saving and emission reduction, the temporary work shed of the construction site adopts the assembled steel structure, which not only has good mechanics performance, safety and reliability, but also can be prefabricated in advance in the factory, and then transported to the site and assembled by bolts. After a construction is completed, it is convenient to disassemble and transport to the next construction site to continue to use, with high repetition rate and in line with China's sustainable development strategy.

\section{Application status of temporary work shed}

At present, there is no uniform standard and specification for the design and construction of the temporary work shed of construction site in China. Therefore, there are various kinds of temporary work shed in each construction site. Through field research, we find that there are four main forms: The first is to use long steel tube as column, diagonal brace, cross bar and floor sweeping rod through the fastener connected to a rectangular frame, finally, a protective structure is composed of short steel tube and fastener is arranged above the frame, the specific structure form is shown in figure 1 to figure 3; The second is the angle steel combination into lattice column by welding, which is fixed on the concrete foundation by expansion bolts, and the protective structure and diagonal brace above the column are composed of steel tubes and fasteners, the specific structure form is shown in figure 4; The third is to use the larger square steel tube as the column and beam, and the bolt is connected to the rectangular steel frame, the smaller square steel tube as the top protective structure, in addition to some of the end plate and the connector in advance of welding, and the other components are all spliced together by bolts, the specific structure form is shown in figure 5 to figure 7 ; The fourth type is made of square steel tube column and I-shaped steel beam to form T-shaped section, the 
beam-column is connected with diagonal bracing, and the protective structure is arranged above the T-section, and the specific structure form is shown in figure 8 .

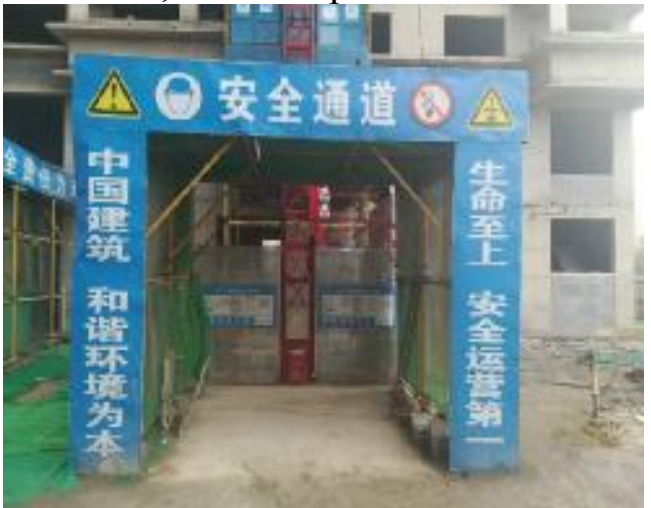

Figure 1. Safety passage of a project in Hebei province of China

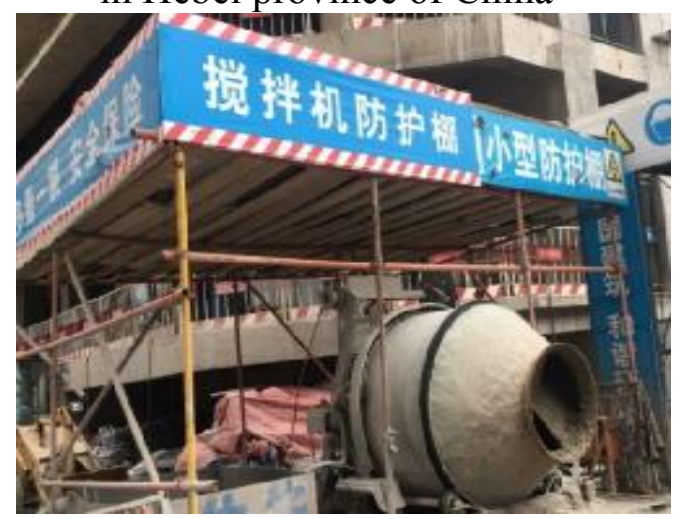

Figure 3. Protective shed of a project

in Liaoning province of China

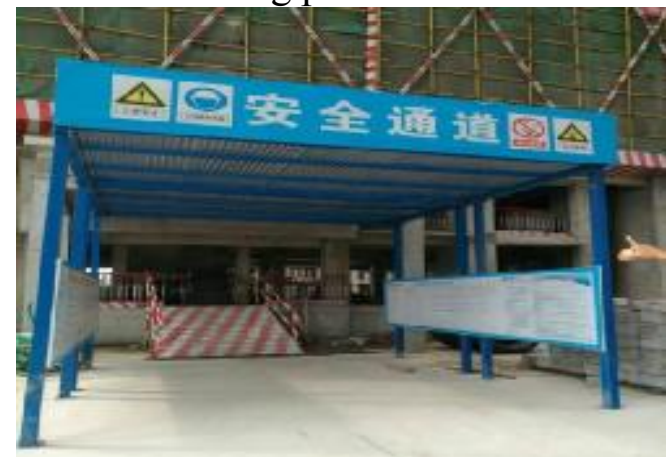

Figure 5. Safety passage of a project in Hubei province of China

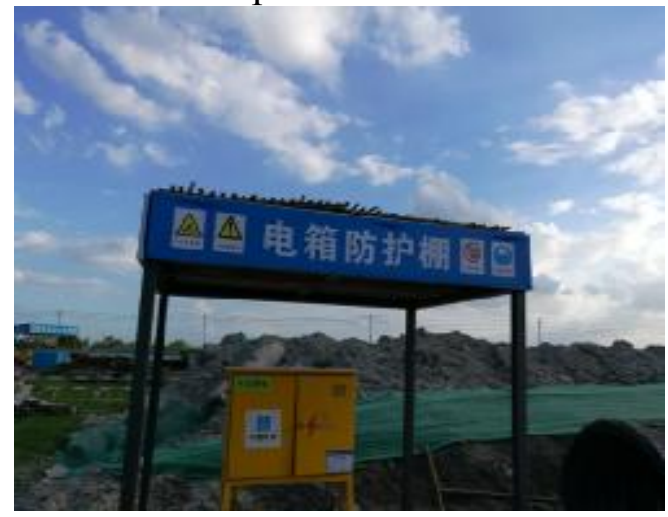

Figure 7. Protective shed of a project in Zhejiang province of China

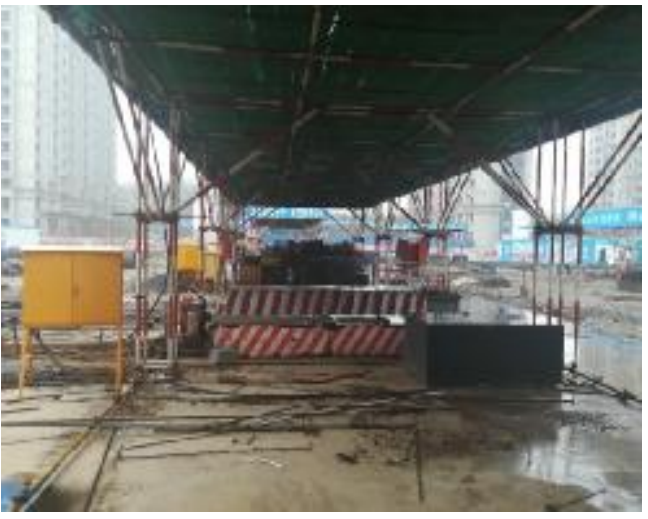

Figure 2. Rebar processing shed of a project in Henan province of China

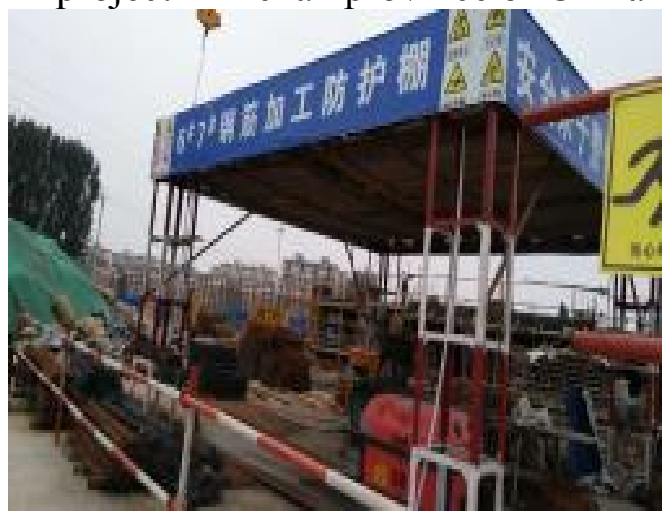

Figure 4. Rebar processing shed of a project in Henan province of China

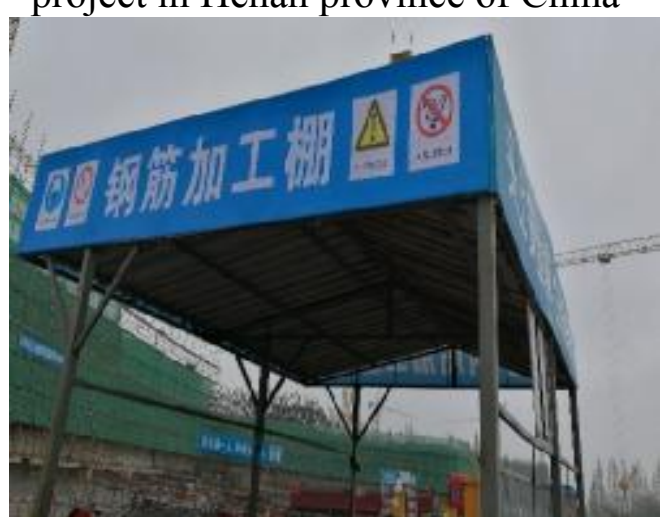

Figure 6. Rebar processing shed of a project in Zhejiang province of China

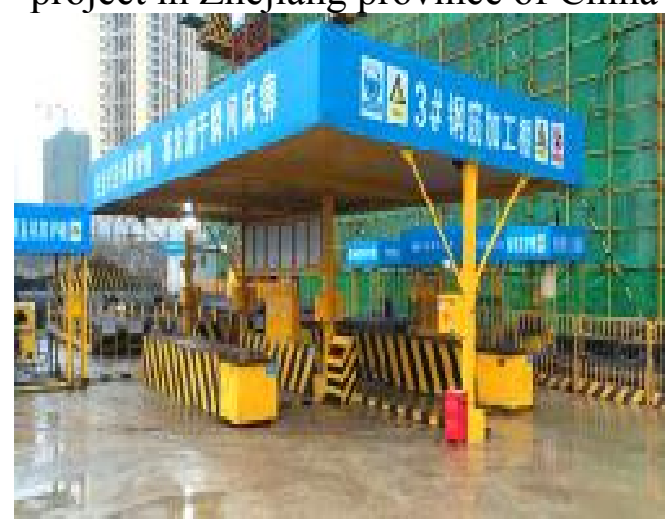

Figure 8. Rebar processing shed of a project in Shangdong province of China 
In summary, the design and construction of temporary work shed is not in conformity with the advocated factory prefabrication of China, on-site splicing and assembly, and repeated recycling of green construction concept of prefabricated steel structure. And there are the following problems: slow assembly, poor security, low reusable rate, preventing rain and anti-smashing structure is not in place, the standard is not uniform at the same construction site, and the main components of the temporary work shed meeting different functional requirements cannot be universal.

\section{Development of Patent Technology of Temporary Work Shed}

Rebar processing shed. Rebar, as the skeleton of concrete, is widely used in building structures. Before pouring concrete, it must be made into a skeleton of certain specifications and forms, and then put it into the template. To make rebar skeleton, it is necessary to stretch, straighten, cut, bend and connect the rebar. In order to meet the requirements of the construction site, the placement of rebar processing equipment and ensure the safety of workers, it must be set up a reasonable rebar processing shed in the design of construction organization.

Wang Junru et $\mathrm{al}^{[2]}$ of Chongqing Chengjian Holding Co. Ltd invented an work shed applied to a construction site, Wei Tianwei et $\mathrm{al}^{[3]}$ of China Construction Second Engineering Bureau Co. Ltd invented a non-side vertical pole rebar processing shed, both of them are made of round steel tube and fastener connected. The former structure is a traditional rectangular frame, the lower column consists of several steel tubes through fastener, and then the column is fixed on the foundation, the vertical main and auxiliary keels are arranged above the structure. The structure of the latter is T-shaped section, The column is composed of round steel tube is set in the middle and buried in the ground, and the rectangular roof frame is arranged on the top, and then the diagonal bracing rod is connected on both sides. Compared with the traditional rebar processing shed, the structure has non-side vertical pole, so it is convenient for the transportation of rebar.

Chen Shouguo ${ }^{[4]}$ of Shanghai Zhongye Tiangong Construction Co. Ltd invented a detachable rebar processing shed, its structure is similar to the portal frame, column and are connected by high-strength bolts, and the herringbone frame made of angular steel is bolted to the sides of the columns and then connected purlin between roof truss, finally laying steel plate above the purlin. The structure is easy to disassemble and assemble and can be used repeatedly.

Rui Qiguo et al ${ }^{[5]}$ of China Construction First Engineering Bureau Co. Ltd invented a reusable tool-type bolted rebar processing shed, Zhou Haijun ${ }^{[6]}$ of China Construction Fifth Engineering Bureau Third Construction Co. Ltd invented a shape steel tool rebar processing shed, Yang Guang et $\mathrm{al}^{[7]}$ of China Construction Forth Engineering Bureau Co. Ltd invented an integrated rebar processing shed, the structure of the three sections are T-shaped, columns are used shape steel, the upper rectangular steel frame by bolts and diagonal braces were connected to the top and side wall of the steel column. The rectangular steel frame of the tool type bolted processing shed is composed of the vertical roof truss, and then the double deck roof plate is arranged on the rectangular steel frame, the lower layer is the steel plate, and the upper layer is the board. The rectangular steel frame of the shape steel processing shed is a double layer hard protection composed of round steel tube and fastener on the steel beam above the column. The biggest difference between the rectangular frame layout of integrated rebar processing shed and the former two is that the former two columns are fixed on the concrete foundation, while the latter has no concrete foundation, and it is directly fixed on the steel structure base, and the position of the processing equipment such as the bending hoop machine and the cutting machine is arranged in advance. The columns of the three structures are arranged in the middle, and the space is flexible, it is convenient to the transportation of the finished and semi-finished products of the rebar and improve the construction efficiency.

He Zhiyuan ${ }^{[8]}$ of Hefei Shen'an steel structure building system engineering Co. Ltd invented a full bolt connection rebar processing shed, its structure of the cross-section similar to the double T section, and the two square steel tube column is arranged below, and the top of the double column is connected to the middle of the I-shaped steel beam, and the diagonal bracing is arranged between the columns and 
between the beams and columns. The purlins are connected to the upper flange of the beam through bolts. Finally, the maintenance structure is arranged around the steel beam, which is composed of angle steel, at the same time, it is convenient for the enterprises to hang slogans in the later stage. Its structure is stable, no columns around, convenient transportation of materials, and can improve work efficiency.

Liu Pei et $\mathrm{al}^{[9]}$ of China Construction Seventh Engineering Bureau First Construction Co. Ltd invented an assembled rebar processing shed, Mai Yafeng et a ${ }^{[10]}$ of Xi'an Building Engineering General Corporation invented a prefabricated rebar processing shed, both the structural forms are square tube column set around, and the truss beam is connected above the column. The former is a rectangular truss beam including the side steel beam and the middle steel beam, the side steel beams are connected to both sides of the column by bolts, the middle steel beam vertically connected between any two side steel beams, and according to the shape of steel beam, two layers of light channel steel are used for ceiling protection, the structure is reasonable and easy to disassemble. The latter is a herringbone truss beam welded in the short axis direction of the structural column, and then a steel frame made of steel tube is set up between the truss beams as the protective structure. This structure needs to be welded on-site, install and disassemble is relatively troublesome.

Carpentry Processing Shed. Wood is a large amount of material used in the construction site, mainly used in the template, support and protection structure, after transport to the construction site need to be secondary processing. It is necessary to set up a reasonable carpentry processing shed for the placement of processing equipment and ensure the safety of workers to meet the needs of the construction site in the design of construction organization.

Wang Wei et $\mathrm{al}^{[11]}$ of China Construction Eighth Engineering Bureau Co. Ltd invented a multi-functional stereotype protective shed, the steel column is arranged around the structure, and a double deck main beam is arranged above the column through the bolt and the connecting plate, and a row of secondary beams are arranged vertically in the direction of the main beam, and then the wood board is arranged on the secondary beam. The protective shed adopts the double-beam structure, which increases the stability of the processing shed, and has the advantages of simple installation and disassembly, and diversified functions, and not only can be used for the carpentry processing shed, but also used for the rebar processing shed, the safety passage and the tea kiosk etc of the construction site.

Guo Min et al ${ }^{[12]}$ of China Construction Second Engineering Bureau Co. Ltd invented a turnover type carpentry processing shed, the structure is composed of vertical beam, bottom beam, top beam and upper protective structure. Finally, the bottom plate, the side plate and the steel hanging ring are respectively fixed to the bottom, the side and the top of the steel frame. The processing shed of the structure can be directly lifted to the appropriate area through tower cranes and other means of transport along with the construction needs, thus avoid the disadvantages of the repeated installation of the processing shed caused by the site arrangement.

Safety Passage. Safety passage in the construction site is an important measure to ensure the safety of the workers, it is set for the staff to walk, transport materials and work pieces. The structure forms are surrounded by columns, and the beams are set up between columns to form a rectangular frame, it is usually arranged at the entrance of the building or the pedestrian passage within the falling radius of the object around the building.

Qiu Guobao et al ${ }^{[13]}$ of China Construction Seventh Engineering Bureau Co. Ltd invented a new type of safety passage for building construction, the structure of which is rectangular frame. The steel plate is used at the bottom, and then the channel steel is welded on the steel plate to connect the inside and outside four rows of square steel tube columns. A double-layer protective skeleton is composed of channel steel and square steel tube is arranged above the column, and two layers of templates are connected to the skeleton respectively. The structure is safe and reliable, but the amount of welding is relatively large on construction site.

Sun Yuelei et $\mathrm{al}^{[14]}$ Tianjin Tianfang Construction Engineering Co. Ltd invented a finalization and detachable building safety passage, Qu Qizhong et $\mathrm{al}^{[15]}$ Tongzhou Construction Group Co. Ltd 
invented a tool-type safety protection passage, both of which have similar cross-sectional forms. The former is connected to a frame between the columns, and covered with wood board over the top of the frame, and then a layer of batten is connected to the top of the column structure, finally, the protective net is arranged on both sides of the safety passage. The latter structure is composed of four vertical columns arranged in the corner and two vertical and horizontal beams between the columns, and then double steel plate is arranged on the beam as a protective structure, and then a set of protective railing is arranged around the protective structure. These two structures are relatively convenient to construct and basically have no on-site welding.

Sai Jinshan et al ${ }^{[16]}$ of China Construction First Bureau Group second Construction Co. Ltd invented a standardized safety passage, Zhang Min et al ${ }^{[17]}$ of Beijing Chengjian seventh Construction Engineering Co. Ltd invented a kind of assembly construction safety passage, both of them are similar in structural forms. Rectangular passage units are bolted together, they are made up of beam, column and diagonal brace. however, the connection between some components is basically bolt-welding. The difference is the arrangement of the upper protective structure, the former is equipped with beam structure of double layer frame, and then the wood board and steel plate are arranged on the upper and the lower beams respectively. The latter adds a layer of safety net over the double protective structure. The connection between the two structural components is complicated, the assembly and disassembly speed is slow.

\section{Conclusions}

In summary, the domestic research on temporary work shed of construction site mainly focuses on the patent technology of utility model, and the theoretical research is relatively few. Among them, there are more utility model patents for rebar processing shed and safety passage, however, the carpentry processing shed is few, and the small equipment protective shed is almost blank. Whether it is the use of temporary work shed on the construction site or the research development of the patent, its structural form and construction methods are different, there is no strict uniform standard of the design and construction, the steel tube fasteners overlap and the welding phenomenon is still common on-site. To solve this problem, it is necessary to design a standard structural form according to the specific requirements of the temporary work shed, which is safe and reliable, easy to install and disassemble, can be used repeatedly, thus greatly reduce energy consumption and carbon emissions of the construction site temporary facilities product, to achieve the purpose of green construction.

\section{Acknowledgements}

This work was financially supported by the National Key Research and Development Program of China (2016YFC0702102).

\section{References}

[1] Shen Z Y, Luo J H, Li Y Q: Progress in Steel Building Structures. Vol.18, No.2(2016), pp. 1-6

[2] Wang J R, Li H T, Hong L, Zhao Z J, etc, China. Patent CN201762998U. (2011)

[3] Wei T W, Wang H Z, Cai M Y, etc, China. Patent CN202954574U. (2013)

[4] Chen S G, China. Patent CN201826541U. (2011)

[5] Rui Q G, Guo S, Yang G, etc, China. patent CN202431011U. (2012)

[6] Zhou H J, China. Patent CN202627582U. (2011)

[7] Yang G, Sun D G, Dong L J, etc, China. Patent CN105525756A. (2016)

[8] He Z Y, China. patent CN205558302U. (2016) 
[9] Liu P, Ren L W, et al, China. Patent CN202787988U. (2013)

[10] Mai Y F, etc, China. Patent CN204326607U. (2015)

[11] Wang W, Liu H H, Zhou M C, etc, China. Patent CN203008439U. (2013)

[12] Guo M, Zeng X H, Yao P-W, etc, China. Patent CN205445017U. (2016)

[13] Qiu G B, Wang H Y, Liu S Q, etc, China. patent CN203452399U. (2014)

[14] Sun Y L, Liu P S, Wen X L, China. patent CN203808492U. (2014)

[15] Qu Q Z, Zhou Z B, Qian D X, etc, China. patent CN204645698U. (2015)

[16] Sai J S, Wang G D, Zhu Y Z, etc, China. Patent CN204983711U. (2016)

[17] Zhang M, Li Y, Lv H, Liang X L, China. patent CN206279783U. (2017) 